\title{
12
}

\section{Do Women Really Desire Casual Sex? Analysis of a Popular Adult Online Dating/Liaison Site}

\author{
Michelle Escasa-Dorne and William Jankowiak
}

\section{Introduction}

Although Hal Scheffler never wrote on sexual behaviour per se, his overall approach in kinship studies lends itself readily to a Darwinian approach to the study of casual sex. To this end, we want to explore the sex differences in men's and women's willingness to seek out casual sexual liaisons. The incidence of casual sex promoted amongst straights appears to be a prominent feature in modern society (Grello, Welsh and Harper 2006; Hatfield, Forbes and Rapson 2011; Lambert, Kahn and Apple 2003; Paul, McManus and Hayes 2000) and has a number of colloquial terms, including 'hooking up' and 'no strings attached' sex. If 'hooking up' (i.e. casual sex with a stranger with no intention of meeting again) has become the preferred and most common form of sexual liaison, it would constitute a historic shift in female sexual behaviour. Moreover, the pervasiveness of popular 'dating' sex sites poses a potential challenge to evolutionary theory of human sexuality that has consistently documented sex differences in male and female erotic perception, imagination and behaviour (Baumeister, Catanese and Vohs 2001). 
In this chapter, we investigate Adult Friend Finder, a large popular sex site-it claims to be the largest online sex and swinger personals community website in the world. It is consistently ranked between the 40th and 60th most visited website on the Internet with claims to over 20 million members. If there is a shift in sexual attitude amongst females in terms of their openness to casual sexual liaisons, their online profiles should be more explicit in stating a desire for entering into a casual sexual encounter.

\section{Sex differences: An overview}

A large body of evidence supports general expectations concerning sex differences in perceptions of sexual behaviour and psychology. An early compilation of various surveys, primarily from the United States (US), suggests that men prefer young, healthy and physically attractive partners, whereas women seek ambitious, generous and socially and economically successful partners when evaluating potential mates (Symons 1979). Related research finds males more than females utilise prostitutes, consume pornography, require less time before consenting to sex and sex with a stranger, and display higher rates of sex with farm animals (Gray and Garcia 2013; Mealey 2000). Differences are further manifested in men having more spontaneous thoughts about sex, a greater variety of sexual fantasies, greater frequency of wanting intercourse and with a larger number of partners, and higher participation in masturbation (even in societies that strongly discourage it) (Baumeister, Catanese and Vohs 2001: 242). In contrast, women give greater weight to cues of emotional intimacy with someone who is open to establishing an ongoing relationship (Buss 2003; Regan and Berscheid 1999; Schmitt, Shackelford and Buss 2001).

Sexual selection theory and data on sexuality suggest that heterosexual women's short-term sexual strategies may be motivated by accumulation of resources (Buss 2008; Hrdy 1999; Symons 1979; Townsend 1998), mate switching (Betzig 1989), or out of a desire to evaluate a prospective long-term mate (Buss 2008; Buss and Schmitt 1993; Greiling and Buss 2000; Meston and Buss 2007) rather than motivation to find momentary sexual pleasure. However, the emergent research on bisexual women finds they have on average more sexual partners than heterosexual or lesbian women. This research also finds that bisexual women often have higher 
testosterone levels than women in the general population (Lippa 2006). The higher testosterone levels may contribute to bisexual women having a stronger sex drive and thus desire to seek out more opportunities for short-term sexual encounters. Another exception is female swingers, or married women, who seek out sexual variety within spouse exchange contexts (Jankowiak and Mixson 2008). In this setting, women engage in casual sexual encounters that allow for the possibility of a physiological release, while also signalling to themselves and others that they are sexually attractive and therefore desirable (see Gangestad and Simpson 2000). Previous literature has also noted that extra-pair mating may be the stimulus necessary to activate women's short-term mating strategies (Pillsworth and Haselton 2006). Clearly, some women do engage in short-term mating encounters.

Although popular media has highlighted 'hooking up' as constituting a new trend whereby females avidly seek out casual sexual trysts, empirical research continues to find persistence sex differences, more men than women are seeking short-term sexual encounters (Garcia and Reiber 2008). Moreover, academic research regarding the 'hooking up' experience on college campuses finds young women overwhelmingly complaining that a 'one-night stand' is not emotionally satisfying (Bogle 2008; Campbell 2008; Garcia and Reiber 2008). College men seldom voiced a similar complaint (Townsend 1998). It is, thus, puzzling to find a proliferation of sexually oriented dating websites claiming that every locality has females eager to engage in casual sex encounters.

In the 1990s, due to the increased popularity of the web, there appeared numerous sex sites that advertised as being links for individuals who want to engage in nonmonetary 'no strings' casual sexual encounters. These websites were designed to provide a means for individuals interested in a short-term sexual tryst to more effectively 'hook up'. Moreover, these dating sites appear to be highly profitable. The ubiquity of the online sex sites raises an intriguing question: Are the participating women harbingers of an emerging shift in American female sexual behaviour? This raises other related questions: Who uses these sites? Is there a difference in the profiles of males and females? In what way, if any, do the well-documented sex differences continue to be manifested in profile ads or is there a striking transformation in females' public sexual persona? To this end, we hypothesised: 
1. If a shift has occurred, straight and bisexual females' ads on the casual sex dating site will be more explicit in stating their desire for a casual, noncommittal sexual encounter.

2. If sex differences continue to be present, female profiles will have more qualifications and stipulations that seek to obtain evidence of a male's interest in forming an emotional attachment.

3. If sexual orientation and, thus, hormonal difference is a factor, there should be more bisexual women's ads compared to straight female profiles stating a preference for casual sexual encounters.

4. Because coitus is a favour women grant men, their ability to control the pace of a relationship ensured their profiles would be more explicit in stating their expectations and, thus, preference for a specific sex act or acts. Conversely, males' desire for some kind of sexual encounter contributes to the writing of a more flexible and, thus, less precise or demanding profile requesting a specific sex act or acts.

\section{Methods}

We assumed that people who advertise on casual dating sites were not representative of typical American males or females. However, cultural anthropologists have historically sought to identify emergent cultural patterns in the behaviours of what could be considered to be sociologically marginal individuals. It is something of a truism that what was once marginal often, in time, becomes a new mainstream cultural pattern. In this way, it is fruitful to investigate the possibility that online casual sex dating sites may represent the nascent presence of a new behavioural pattern within America's regional cultures.

Adult personal websites allow individuals to create a profile to advertise their availability and seek other individuals who may be interested in the same type of relationship or activities as themselves. Similar to other largeprofile dating websites, such as Match.com or Chemistry.com, individual profiles include photographs, descriptive information from chosen categories and written information providing additional information about the individual and the type of person he or she is seeking. Unlike websites tailored to find a relationship (or, more directly, to 'find love', as one popular dating outlet states), adult online dating sites advertise themselves as websites to find sexual partners. While the layout of the adult dating site may be similar to other dating websites, the content, 
photographs and expectations are typically more sexually inclined and quite explicit in an individual's phrasing of what he or she is looking for in a partner. For example, 80 per cent of female profiles contain a photo(s) that had semi or full nudity, with 78 per cent of the ads containing sexually explicit words or phrases that would have been deleted had they been expressed on a mainstream media outlet. In this and many other ways, sex dating/liaison sites differ from eHarmony.com and Match.com.

Given the online sex sites' sexual explicitness, we assumed that men and women who placed an ad should have had a greater interest in short-term mating encounters compared to men and women who use more standard and socially respected dating sites (e.g. Match.com and eHarmony.com). Many other outlets for finding casual sexual encounters are available via websites. For this project, we focused on Adult Friend Finder for several reasons. While Craigslist offers a section for casual encounters, a large number of postings were found to be hinting towards prostitution. One new site, Ashley Madison, has gained recent popularity due to the specific nature of the website in offering an outlet for individuals who are already partnered or married and who are looking for an extra-partner affair. Because our intent was to focus on the mating preferences of females and males who are not currently partnered, we did not further analyse profiles in AshleyMadison.com. Given the commonality between these sites, we are confident that the adult dating we focused on is highly representative of other non-prostitution oriented, online sex dating services.

To test our hypotheses, the authors collected data from individuals' profiles on a large, casual sex dating website. The site is highly profitable and is found around the world (e.g. in Europe, Asia and Africa). The website defines itself as an 'adult personals' website where individuals can create a profile to advertise their availability and seek other individuals who may be interested in the same type of relationship or activities as themselves. The casual sex site offers two membership options: a 'silver' membership at approximately US $\$ 30$ per month and a 'gold' membership at US\$50 per month. A silver member has a limited amount of times they may contact other members, while a gold member has unlimited access to look at and respond to ads. Due to the initial uncertainty regarding individual or profile differences between gold and silver members, profiles were selected from each category equally. After an initial analysis, there were no differences between the gold and silver profiles in the prose, photo type, content or type of sexual encounter/relationship requested. We combined the two types of profiles for analysis. 
Sample methods included a randomised selection of male and female profiles from a variety of geographical regions in continental US. The regions we sampled included the east, south, midwest and western US. We selected four states from each region. These states in alphabetical order are California, Florida, Georgia, Illinois, Indiana, Louisiana, Maine, Massachusetts, Minnesota, Mississippi, Montana, Nevada, New York, Ohio, Pennsylvania and Utah. Analyses showed no differences in sexual or relationship profile content by region. Certain cultural styles were evident in local areas. As an example, there were a larger number of beach photographs and surfer images in California and Florida profiles over the other states. In total, 50 ads ( 25 gold and 25 silver levels) per gender were selected by coding every third page on the website within the respected gold and silver categories. This provided an original sample of 1,508 profiles, which included an equal number of males and females.

The site asks individuals to list their age, height, body type, educational level, race and sexual orientation from a set selection of choices. In many cases, members are given the option to refuse disclosure of such information. Sexual orientation was by far the category most often checked as 'prefer not to say'. We treated these ads as a separate category unless we were able to determine their orientation from information in their profile. In most cases, we were able to determine a person's sexual orientation if they were seeking men, women or both. There were 13 incidences where a profile listed 'prefer not to say' concerning an individual's sexual orientation, yet had a profile statement that explicitly stated a preference for sex with males and females. In these instances the person was recoded as having a bisexual orientation.

There were four primary sexual orientations: heterosexual, homosexual, bisexual and bicurious (i.e. women who thought about but had not participated in a same-sex sexual encounter). We dropped from our sample the six homosexual profiles (i.e. profiles stating they were only interested in a same-sex partner) that had been erroneously included by the dating site in the heterosexual category. We kept the categories of bisexual, bicurious and heterosexual. Of these categories, 57 per cent of the females and 76 per cent of the males described themselves as heterosexual. The percentages of bicurious and bisexual females were modest (17.2 and 21.6 per cent, respectively), while males self-coded themselves in these categories to a lesser degree (6.9 and 6.6 per cent, respectively). A small number of males (10 per cent) and females ( 5 per cent) did not disclose sexual orientation nor were researchers able to classify their sexual 
orientation based on profile content. In these instances, we dropped the profiles from our sample. ${ }^{1}$ Further details of the breakdown of our sample size categories can be seen in Table 3 .

Table 3. Descriptives of the sample

\begin{tabular}{|c|c|c|}
\hline & Females $^{a}$ & Males $^{\mathrm{a}}$ \\
\hline \multicolumn{3}{|l|}{ Age } \\
\hline $18-24$ & $40(7.3)$ & $36(5.3)$ \\
\hline $25-29$ & 67 (12.3) & $92(13.6)$ \\
\hline $30-34$ & $130(23.8)$ & $127(18.8)$ \\
\hline 35-39 & $130(23.8)$ & $163(24.1)$ \\
\hline 40-44 & $86(15.8)$ & $104(15.4)$ \\
\hline $45+$ & $93(17)$ & $155(22.9)$ \\
\hline \multicolumn{3}{|l|}{ Ethnicity } \\
\hline Caucasian & $404(74)$ & 537 (79.3) \\
\hline Black & $72(13.2)$ & $81(12)$ \\
\hline Hispanic & $27(4.9)$ & $24(3.5)$ \\
\hline Asian & $8(1.5)$ & $0(0)$ \\
\hline Other/No Data & $35(6.3)$ & $35(4.8)$ \\
\hline \multicolumn{3}{|l|}{ Education } \\
\hline High School & $67(12.3)$ & $71(10.5)$ \\
\hline Associate's Degree & $29(5.3)$ & $25(3.7)$ \\
\hline Some College & $146(26.7)$ & $145(21.4)$ \\
\hline Bachelor's Degree & $220(40.3)$ & $342(50.5)$ \\
\hline No Data & $84(15.4)$ & $94(13.9)$ \\
\hline \multicolumn{3}{|l|}{ Sexual Orientation } \\
\hline Heterosexual & 309 (56.6) & $515(76.1)$ \\
\hline Bicurious & $94(17.2)$ & 47 (6.9) \\
\hline Bisexual & $118(21.6)$ & $45(6.6)$ \\
\hline No Data & $25(4.6)$ & $70(10.3)$ \\
\hline \multicolumn{3}{|l|}{ Body Type } \\
\hline Slim/Petite & $8(1.5)$ & $1(.1)$ \\
\hline Athletic & $99(18.1)$ & $379(56)$ \\
\hline
\end{tabular}

1 Lisa Diamond (2008) argues that bisexuality (she prefers the term nonexclusive) is a deeply problematic category, as 'it is not clear if it refers to sexual identity, sexual behavior or sex orientation' (ibid.: 13). 


\begin{tabular}{|l|c|c|}
\hline & Females $^{\mathrm{a}}$ & Males $^{\mathrm{a}}$ \\
\hline Average & $173(31.7)$ & $227(33.5)$ \\
\hline Extra Padding & $188(34.4)$ & $53(7.8)$ \\
\hline Ample & $68(12.5)$ & $10(1.5)$ \\
\hline Not Determinable & $10(1.8)$ & $7(1)$ \\
\hline TOTAL & $546(100)$ & $677(100.1)$ \\
\hline
\end{tabular}

a. Listed as $n$ (\% within gender)

Source: Collated from data collected by the authors. (c) Michelle Escasa-Dorne, 2014.

Research on the validity of online nonsexual dating sites finds a great deal of 'deception' with facts (Toma, Hancock and Ellison 2008; Hatfield, Forbes and Rapson 2011). For example, men tend to exaggerate their height, income and occupation, whereas women misrepresent their age, level of physical attraction and whether they have children. For the purposes of this study, we assumed that if and when individuals exaggerated the 'facts' in their profiles, it should be in the direction of what they truly value, prefer and want in a sexual encounter.

The researchers printed and then coded each profile by analysing the content of the profiles, as well as the listed relationship type and/or activities sought. Of our initial 1,508 profiles, there were 141 vague ads (e.g. had minimum or no information on what they wanted). These ads were dropped from our sample. Fourteen ads, all from females, were clearly about prostitution (i.e. ads acknowledging they would do ANYTHING in exchange for these special gifts). These ads were also dropped from the sample. We also identified (as stated in a person's ad) 130 swinger or spouse-exchange requests. The majority of swinger ads stated both partners were involved in creating the profile. Thus, we did not include swingers in the final analysis. However, we included men and women who claimed to be divorced, soon to be divorced or just married. After dropping the prostitution, swinger and vague ads, our original sample was reduced to 677 males and 546 females $(n=1,223)$. We did not conduct an in-depth survey of who actually used the site, thus we cannot be certain who actually engaged in casual sexual encounters. Our pilot survey, albeit large, is suggestive and not conclusive. 
Five researchers served as coders of the individuals' profiles. We coded relationship type as 'casual', 'conflicted' or 'long-term/romantic' (LTR). Profiles were coded as LTR when individuals stated a preference for a continuous 'relationship' (e.g. going out on multiple dates, being friends first, emphasising having to know and trust a person, etc.). Moreover, individuals who were classified as having an LTR profile emphasised they were not looking for flings, promiscuous sex or one-night stands, but were more interested in developing a continuous, ongoing mutual relationship. Casual ads stressed a preference to meet numerous members of the preferred sex, did not mention a preference to establish an ongoing relationship and emphasised a desire for sexual satisfaction. Conflicted profiles included individuals seeking what the site refers to as a 'friends with benefits' relationship (these were identified from key phrases in profiles that highlighted a preference for establishing some type of emotional involvement). For women, this included a partner who would be available for a weekend of walks, talks, dinner, movies and sex; whereas for men, 'friends with benefits' usually meant wanting a sex partner who would meet at an appointed place for an allotted amount of time. Some of the ads contained mixed or conflicting messages in their profile statement. These mixed messages stressed different and, often contradictory, motives (e.g. a desire for a boyfriend and in a separate paragraph 'no strings attached' sex). Whenever a profile contained conflicting goals (i.e. wanting a casual sex encounter as well as a long-term relationship), the profile was coded as a conflicted profile.

All data were analysed using SPSS 16.0 for Windows. Except where stated, all analyses used a Chi-squared goodness of fit test and all tests assumed an alpha of 0.05 .

\section{Results}

The motivation for being on the sex site significantly differs by gender $\left(\chi^{2}=125.01, d f=2, p<.001\right)$. Females' profiles were more likely to seek an LTR than males' profiles (see Table 4). Male profiles overwhelmingly (52 per cent, $n=350$ ) emphasised a desire for casual sex compared to only 26 per cent (143) of female profiles. Conflicted profiles were fairly evenly distributed between males and females. These findings suggest that female profiles were less explicit in stating a desire for casual sex, while male profiles appeared more open to anonymous or casual sex. 
Post-hoc tests reveal a pattern in women's profiles based on sexual orientation. When profiles of heterosexual women were separated from bisexual and bicurious women a significant pattern emerged —of the heterosexual women $(n=309)$, only 19.4 per cent $(n=60)$ sought a casual relationship. Comparatively, of the bicurious and bisexual women, 36 per cent $(n=77)$ sought a casual relationship. Forty per cent of straight women preferred a long-term romantic relationship, compared to an average of only 20 per cent for the bisexual and bicurious women (see Table 6). Further, bisexual profiles often expressed a preference to form an emotional monogamous relationship with one sex, while stating a preference for casual encounters with the other sex.

We also examined evidence of associations between individual physical characteristics and stated motives on the sex site. For these post-hoc analyses, we sought to see if there is a relationship between age, body type (e.g. thin, athletic, average and a few extra pounds) and degree of openness to casual sexual encounters. We found a positive statistical association between body type and relationship desired for females $\left(\chi^{2}=\right.$ 27.10, $d f=10, p=.003)$ but not for males $\left(\chi^{2}=6.70, d f=10, p=.753\right)$ (see Table 3). There was, however, an association between age of the subject and relationship desired for both males $\left(\chi^{2}=33.778, d f=15\right.$, $n=677, p=.004)$ and females $\left(\chi^{2}=40.700, d f=15, n=546, p<.001\right)$ (see Table 4).

Of all the females who were between the ages of 18-24 $(n=40)$, 17 (43 per cent) expressed an interest in casual sex versus six (15 per cent) who were looking for an LTR relationship. Of the 93 females who were 45 and above, 46 were coded as seeking an LTR relationship ( 49.5 per cent) while only 11 (or 12 per cent) wanted variety or casual sex.

All profiles were coded to determine whether there was a difference between males and females seeking or offering specific services, sexual or nonsexual (e.g. conversation, hugs, or dinner dates), from potential partners $\left(\chi^{2}=109.568, d f=4, n=546, p<.001\right)$. Only 7 per cent $(n=38)$ of females offered services, compared to 19 per cent $(n=131)$ of males. In the context of a potential first-time sexual encounter, males tended to be less demanding and were more willing to provide noncoitus sexual services. Based upon this evidence, hypothesis 4 is supported. 
Table 4. Type of encounter sought by males and females

\begin{tabular}{|c|c|c|c|c|c|c|c|c|}
\hline Motives & Males $^{a}$ & Females $^{a}$ & $n$ & $\chi^{2}$ & $d f$ & $p$ & & \\
\hline LTR $^{*}$ & $\begin{array}{r}66 \\
(9.7) \\
\end{array}$ & $174(31.9)$ & \multirow{5}{*}{1223} & \multirow{5}{*}{130.915} & \multirow{5}{*}{3} & \multirow{5}{*}{$<.001$} & & \\
\hline Conflicted & $\begin{array}{r}165 \\
(24.4)\end{array}$ & $\begin{array}{l}120 \\
(22)\end{array}$ & & & & & & \\
\hline $\begin{array}{l}\text { Friends with } \\
\text { Benefits }\end{array}$ & $\begin{array}{r}96 \\
(14.2) \\
\end{array}$ & $\begin{array}{l}109 \\
(20) \\
\end{array}$ & & & & & & \\
\hline Casual/Variety & $\begin{array}{r}350 \\
(51.7) \\
\end{array}$ & $143(26.2)$ & & & & & & \\
\hline TOTAL & $\begin{array}{r}677 \\
(100) \\
\end{array}$ & $\begin{array}{r}546 \\
(100) \\
\end{array}$ & & & & & & \\
\hline \multicolumn{9}{|c|}{ Motives by Body Type } \\
\hline & $\mathrm{LTR}^{\star \mathrm{b}}$ & Conflicted $^{\mathrm{b}}$ & $\mathrm{FB}^{\star \star b}$ & Casual $^{\text {b }}$ & $n$ & $\chi^{2}$ & $d f$ & $p$ \\
\hline Males & & & & & 677 & 11.535 & 15 & .714 \\
\hline Small/Petite & $0(0)$ & $0(0)$ & $0(0)$ & $1(100)$ & & & & \\
\hline Average & $\begin{array}{r}21 \\
(9.3) \\
\end{array}$ & $\begin{array}{r}59 \\
(26) \\
\end{array}$ & $\begin{array}{r}42 \\
(18.5) \\
\end{array}$ & $\begin{array}{r}105 \\
(46.3) \\
\end{array}$ & & & & \\
\hline Athletic & $\begin{array}{r}37 \\
(9.8) \\
\end{array}$ & $\begin{array}{r}88 \\
(23.2)\end{array}$ & $\begin{array}{r}47 \\
(12.4)\end{array}$ & $\begin{array}{r}207 \\
(54.6)\end{array}$ & & & & \\
\hline Ample & $1(10)$ & $3(30)$ & $0(0)$ & $6(60)$ & & & & \\
\hline Extra Padding & $\begin{array}{r}6 \\
(11.3) \\
\end{array}$ & $\begin{array}{r}14 \\
(26.4) \\
\end{array}$ & $\begin{array}{r}5 \\
(9.4) \\
\end{array}$ & $28(52.8)$ & & & & \\
\hline No Data & $\begin{array}{r}1 \\
(14.3) \\
\end{array}$ & $\begin{array}{r}1 \\
(14.3) \\
\end{array}$ & $\begin{array}{r}2 \\
(28.6) \\
\end{array}$ & $\begin{array}{r}3 \\
(42.9) \\
\end{array}$ & & & & \\
\hline Females & & & & & 546 & 30.813 & 15 & .009 \\
\hline Small/Petite & $\begin{array}{r}5 \\
(62.5) \\
\end{array}$ & $\begin{array}{r}1 \\
(12.5) \\
\end{array}$ & $\begin{array}{r}0 \\
(0)\end{array}$ & $\begin{array}{r}2 \\
(25) \\
\end{array}$ & & & & \\
\hline Average & $\begin{array}{r}65 \\
(37.6) \\
\end{array}$ & $\begin{array}{r}37 \\
(21.4) \\
\end{array}$ & $\begin{array}{r}27 \\
(15.6) \\
\end{array}$ & $44(25.4)$ & & & & \\
\hline Athletic & $\begin{array}{r}29 \\
(29.3) \\
\end{array}$ & $\begin{array}{r}20 \\
(20.2) \\
\end{array}$ & $\begin{array}{r}13 \\
(13.1)\end{array}$ & $37(37.4)$ & & & & \\
\hline Ample & $\begin{array}{r}12 \\
(17.6) \\
\end{array}$ & $\begin{array}{r}20 \\
(29.4)\end{array}$ & $\begin{array}{r}20 \\
(29.4)\end{array}$ & $16(23.5)$ & & & & \\
\hline Extra Padding & $\begin{array}{r}61 \\
(32.4) \\
\end{array}$ & $\begin{array}{r}38 \\
(20.2) \\
\end{array}$ & $\begin{array}{r}46 \\
(24.5) \\
\end{array}$ & $43(22.9)$ & & & & \\
\hline No Data & $2(20)$ & $4(40)$ & $3(30)$ & $1(10)$ & & & & \\
\hline
\end{tabular}


FOCALITY AND EXTENSION IN KINSHIP

\begin{tabular}{|c|c|c|c|c|c|c|c|c|}
\hline \multicolumn{9}{|c|}{ Motives by Age } \\
\hline & $\mathrm{LTR}^{\star \mathrm{c}}$ & Conflict $^{c}$ & $\mathrm{FB}^{\star \star c}$ & Casual $^{c}$ & $n$ & $\chi^{2}$ & $d f$ & $p$ \\
\hline Males & & & & & 677 & 33.778 & 15 & .004 \\
\hline $18-24$ & $\begin{array}{r}4 \\
(11.1) \\
\end{array}$ & $\begin{array}{r}11 \\
(30.6) \\
\end{array}$ & $\begin{array}{r}1 \\
(2.8) \\
\end{array}$ & $20(55.6)$ & 36 & & & \\
\hline $25-29$ & $\begin{array}{r}5 \\
(5.4) \\
\end{array}$ & $\begin{array}{r}18 \\
(19.6) \\
\end{array}$ & $\begin{array}{r}10 \\
(10.9) \\
\end{array}$ & $59(64.1)$ & 92 & & & \\
\hline $30-34$ & $\begin{array}{r}4 \\
(3.1)\end{array}$ & $\begin{array}{r}34 \\
(26.8)\end{array}$ & $\begin{array}{r}16 \\
(12.6)\end{array}$ & $73(57.5)$ & 127 & & & \\
\hline 35-39 & $\begin{array}{r}16 \\
(9.8)\end{array}$ & $\begin{array}{r}39 \\
(23.9)\end{array}$ & $\begin{array}{r}19 \\
(11.7)\end{array}$ & 89 (54.6) & 163 & & & \\
\hline $40-44$ & $\begin{array}{r}15 \\
(14.4) \\
\end{array}$ & $\begin{array}{r}28 \\
(26.9) \\
\end{array}$ & $\begin{array}{r}20 \\
(19.2) \\
\end{array}$ & $41(39.4)$ & 104 & & & \\
\hline $45+$ & $\begin{array}{r}22 \\
(14.2) \\
\end{array}$ & $\begin{array}{r}35 \\
(22.6) \\
\end{array}$ & $\begin{array}{r}30 \\
(19.4) \\
\end{array}$ & 68 (43.9) & 155 & & & \\
\hline Females & & & & & 546 & 40.700 & 15 & $<.001$ \\
\hline $18-24$ & $\begin{array}{r}6 \\
(15) \\
\end{array}$ & $\begin{array}{r}11 \\
(27.5)\end{array}$ & $\begin{array}{r}6 \\
(15) \\
\end{array}$ & $17(42.5)$ & 40 & & & \\
\hline $25-29$ & $\begin{array}{r}12 \\
(17.9) \\
\end{array}$ & $\begin{array}{r}21 \\
(31.3) \\
\end{array}$ & $\begin{array}{r}17 \\
(25.4) \\
\end{array}$ & $17(25.4)$ & 67 & & & \\
\hline $30-34$ & $\begin{array}{r}39 \\
(30) \\
\end{array}$ & $\begin{array}{r}21 \\
(16.2) \\
\end{array}$ & $\begin{array}{r}25 \\
(19.2) \\
\end{array}$ & 45 (34.6) & 130 & & & \\
\hline $35-39$ & $\begin{array}{r}43 \\
(33.1)\end{array}$ & $\begin{array}{r}31 \\
(23.8) \\
\end{array}$ & $\begin{array}{r}26 \\
(20) \\
\end{array}$ & $30(23.1)$ & 130 & & & \\
\hline $40-44$ & $\begin{array}{r}28 \\
(32.6) \\
\end{array}$ & $\begin{array}{r}20 \\
(23.3) \\
\end{array}$ & $\begin{array}{r}15 \\
(17.4) \\
\end{array}$ & $23(26.7)$ & 86 & & & \\
\hline $45+$ & $\begin{array}{r}46 \\
(49.5)\end{array}$ & $\begin{array}{r}16 \\
(17.2)\end{array}$ & $\begin{array}{r}20 \\
(21.5)\end{array}$ & $11(11.8)$ & 93 & & & \\
\hline
\end{tabular}

* LTR: Long-term/romantic; ** FB: Friends with benefits/'fuck buddy'

a. listed as $n$ (\% within gender)

b. $n$ (\% within body type)

c. $n$ (\% within age)

Source: Collated from data collected by the authors. @ Michelle Escasa-Dorne, 2014.

Additionally, profiles were coded for instances of listing specific traits desired of a partner. These traits included sexual characteristics or personality characteristics (e.g. wanting someone with certain types or standards of looks, intelligence, sexual openness to specific acts or behaviours, etc.). Profiles of individuals who expressed flexibility in traits or characteristics of a partner were coded as 'trait flexible' (see Table 5). Profiles that were trait flexible were those of females or males that stated they were open to all age groups, looks, backgrounds, etc. In our data, 
both sexes were overwhelmingly trait flexible. We suspect this was due to both sexes wanting to attract the largest number of responses possible. Trait flexibility was reported for 405 females ( 74 per cent), while 139 females (26 per cent) were coded as trait specific. Males followed a similar pattern: 556 men (82 per cent) were trait flexible, with 116 (17 per cent) of the men trait specific.

Table 5. Sexual content of profiles

\begin{tabular}{|l|c|c|c|c|c|c|c|}
\hline $\begin{array}{l}\text { Sexual Content } \\
\text { By Age }\end{array}$ & $\begin{array}{c}\text { Trait } \\
\text { Flexible }^{*}\end{array}$ & $\begin{array}{c}\text { Trait } \\
\text { Specific }\end{array}$ & No Data* & $\begin{array}{c}\text { Total } \\
(\%)^{*}\end{array}$ & $\chi^{2}$ & $d f$ & $p$ \\
\hline Males & $\begin{array}{c}556 \\
(82.1)\end{array}$ & $116(17.1)$ & $5(0.7)$ & & 13.683 & 10 & .188 \\
\hline $18-24$ & $34(6.1)$ & $1(0.9)$ & $1(20)$ & $36(5.3)$ & & & \\
\hline $25-29$ & $78(14)$ & $15.8(12.1)$ & $0(0)$ & $92(13.6)$ & & & \\
\hline $30-34$ & $\begin{array}{c}106 \\
(19.1)\end{array}$ & $21(18.1)$ & $0(0)$ & $\begin{array}{c}127 \\
(18.8)\end{array}$ & & & \\
\hline $35-39$ & $\begin{array}{c}137 \\
(24.6)\end{array}$ & $25(21.6)$ & $1(20)$ & $\begin{array}{c}163 \\
(24.1)\end{array}$ & & & \\
\hline $40-44$ & $79(14.2)$ & $24(20.7)$ & $1(20)$ & $\begin{array}{c}104 \\
(15.4)\end{array}$ & & & \\
\hline $45+$ & $\begin{array}{c}122 \\
(21.9)\end{array}$ & $31(26.7)$ & $2(40)$ & $\begin{array}{c}155 \\
(22.9)\end{array}$ & & & \\
\hline Females & $\begin{array}{c}405 \\
(74.2)\end{array}$ & $139(25.5)$ & $2(0.4)$ & & 9.183 & 10 & .515 \\
\hline $18-24$ & $30(7.4)$ & $10(1.8)$ & $0(0)$ & $40(7.3)$ & & & \\
\hline $25-29$ & $54(13.3)$ & $13(9.4)$ & $0(0)$ & $67(12.3)$ & & & \\
\hline $30-34$ & $99(24.4)$ & $30(21.6)$ & $1(50)$ & $\begin{array}{c}130 \\
(23.8)\end{array}$ & & & \\
\hline $35-39$ & $95(23.5)$ & $35(25.2)$ & $0(0)$ & $\begin{array}{c}130 \\
(23.8)\end{array}$ & & & \\
\hline $40-44$ & $56(13.8)$ & $30(21.6)$ & $0(0)$ & $86(15.8)$ & & & \\
\hline $45+$ & $71(17.5)$ & $21(15.1)$ & $1(50)$ & $93(17)$ & & & \\
\hline
\end{tabular}

* listed as $\mathrm{n}$ (\% within sexual content)

Source: Collated from data collected by the authors. (c) Michelle Escasa-Dorne, 2014.

Twenty of the 60 heterosexual female profiles coded as seeking casual sex had profiles that explicitly stated the woman was coming out of a recent 'sexless' marriage and desiring a relationship that, in the words of a 38-year-old woman, would make her 'feel sexually desired once again'. This is consistent with research that found women prefer sexual validation instead of momentary physiological pleasure (Meana 2010). 
FOCALITY AND EXTENSION IN KINSHIP

Table 6. Females' motives listed by sexual orientation

\begin{tabular}{|c|c|c|c|c|c|}
\hline Motives & Bicurious & Bisexual & Straight & No Data & Total \\
\hline \multicolumn{6}{|l|}{ LTR } \\
\hline Count & 24 & 18 & 124 & 8 & 174 \\
\hline$\%$ within Motives & 13.8 & 10.3 & 71.3 & 4.6 & 100.0 \\
\hline$\%$ within Sexual Orientation & 25.5 & 15.3 & 40.1 & 32.0 & 31.9 \\
\hline \multicolumn{6}{|l|}{ Conflicted } \\
\hline Count & 21 & 26 & 67 & 6 & 120 \\
\hline$\%$ within Motives & 17.5 & 21.7 & 55.8 & 5.0 & 100.0 \\
\hline$\%$ within Sexual Orientation & 22.3 & 22.0 & 21.7 & 24.0 & 22.0 \\
\hline \multicolumn{6}{|c|}{ Friends with Benefits/'Fuck Buddy’' } \\
\hline Count & 22 & 24 & 58 & 5 & 109 \\
\hline$\%$ within Motives & 20.2 & 22.0 & 53.2 & 4.6 & 100.0 \\
\hline$\%$ within Sexual Orientation & 23.4 & 20.3 & 18.8 & 20.0 & 20.0 \\
\hline \multicolumn{6}{|l|}{ Casual } \\
\hline Count & 27 & 50 & 60 & 6 & 143 \\
\hline$\%$ within Motives & 18.9 & 35.0 & 42.0 & 4.2 & 100.0 \\
\hline \% within Sexual Orientation & 28.7 & 42.4 & 19.4 & 24.0 & 26.2 \\
\hline \multicolumn{6}{|l|}{ Total } \\
\hline Count & 94 & 118 & 25 & 309 & 546 \\
\hline$\%$ within Motives & 17.2 & 21.6 & 4.6 & 56.6 & 100.0 \\
\hline \% within Sexual Orientation & 100.0 & 100.0 & 100.0 & 100.0 & 100.0 \\
\hline
\end{tabular}

$\left(\chi^{2}=36.360, d f=9, p<.001\right)$

Source: Collated from data collected by the authors. () Michelle Escasa-Dorne, 2014.

Finally, there is little sex difference in ad content across all the US regions coded. If a state had a fluid or static migration pattern or high or low percentage of college graduates, male and female, the ads are strikingly similar.

\section{Discussion}

Camille Paglia points out that 'since the sexual revolution of the 1960s, American society has become increasingly secular, with the media environment drenched with sex' (2010: A23). The cultural shift away from sexual restraint to a greater openness and tolerance in public expression of sexual desire does not mean there has been a corresponding shift in 
women's sexual behaviour. Edward Laumann et al.'s (1994) extensive survey of sexual behaviour in the US did not find strong evidence for this nor did our online study of female sexual preferences. The majority of heterosexual women's profiles, regardless of the degree of sexual explicitness, overwhelmingly noted a preference for sex within some type of ongoing or imagined relationship. In this way, evidence for heterosexual women's preference for 'no strings attached' sex, or, sexual variety for its own sake, continues to be absent. This is consistent with other studies (Buss 2008; Jankowiak, Gray and Hatman 2008; Schmitt, Shackelford and Buss 2001; Symons 1979; Townsend 1998) that repeatedly found women to be the choosier sex, showing overwhelming preference for some form of a 'relationship partner' over an anonymous 'one-night stand' sexual encounter.

Kathleen Bogle's (2008) research on contemporary college 'dating' provides another correction to the media's assertion that there has been a fundamental shift in female sexual behaviour. Her research found female casual sexual encounters were confined to their college years. Upon graduation, men and women returned to more conventional forms of dating in an effort to find a long-term mate. Further, Bogle reports that college women who did engage in numerous casual sexual encounters showed disappointment, regret and remorse. For most American women a 'one-night stand' produced an acute negative emotional reaction (as opposed to a moral objection).

Russell Clark's (1990) research found that heterosexual women had no problem dating a stranger; however, they did have a problem immediately having sex with a stranger. John Townsend's (1998) ethnographic study of American women's 'one-night stand' dating behaviour found a similar negative reaction. In a different but related study, Townsend and Wasserman (1998) found American women required more information than men in order to make the decision to have sex with someone. In this way, women required some form of contextualisation, imaginary or real, before entering into a sexual encounter with a stranger. Highlighting the importance of communication and trusting a sex partner, when women could talk with their sex partner about their experience with him, they were able to personalise that experience and were thus less troubled with entering into a casual sexual encounter (Paul and Hayes 2002). Women's need to be able to, in some fashion, 'control' the way they participated in a sexual encounter was also evident among American female swingers who did not immediately select the first attractive male they saw, but, 
rather, preferred to wait and discuss things with their husband, meet with the desired individual(s), exchange small talk and then, and only then, decided to have or not have sex (Jankowiak and Mixson 2008).

In contrast, men, especially men in their 20s, remained keenly focused on seeking out a variety of sex partners. It is a motivation that makes young men more than any other age cohort attracted to finding 'no strings attached' sex opportunities. As men age, however, we found a shift in their use of language away from an exclusive emphasis on 'no strings attached' sex to one more open to the possibility of forming an ongoing relationship (Table 4). Is this shift in men's language representative of a shift in male sexual desire or evidence only of a shift among more mature or experienced males in their understanding of what females want? We suspect it may be a little of both. As men learn that women do not want 'no strings attached' sex, they also realise they too want some of the emotional benefits that can only be gained from being in an ongoing relationship. However, women's conflicted profiles may be nothing more than a by-product of a new cultural tolerance toward the acknowledgement, if not advertisement, of an interest in sexual pleasure.

It could be argued that these mixed signals found in the female profiles are the by-product of an individual female making a nod toward fitting into a cultural role of dampened sexual desire, while preferring to engage the newer ethos of sexual frankness, sexual exploration and sexual casualness. In this way, the conflicted profiles may represent nothing more than a partial presentation of a proper persona. If this interpretation is correct, how can we account for the low frequency of mixed messages among the bisexual profiles? After all, bisexual women who have been socialised within similar age cohorts and live across the US in similar communities should have internalised a similar sexual script concerning social propriety and sexual respectability. Why then, were their profiles more direct as to their interest in and desire for casual sex? In every way, bisexual women's profiles were closer to heterosexual men's profiles than they were to heterosexual women's profiles.

It is revealing that of the females who expressed the strongest preference for partner variety, the majority of the females are bisexual. It is significant that 54 per cent of females who stated or strongly hinted at wanting 'no strings attached' sex were bisexual/bicurious. This is a rather high percentage and requires further commentary. 
We did not anticipate that bisexual females would be the most prominent users on the dating site. It is consistent, however, with studies that find a strong relationship between higher testosterone and enhanced sexual desire (van Anders, Hamilton and Watson 2007). There is also a relationship between testosterone and sexual activity itself - it has been noted postmenopausal women using testosterone patches reported an increase in sexual activity (Bergner 2009: 5). Other research has found that bisexual women tend to have higher levels of testosterone, which may contribute to their having a stronger sexual desire (Brizendine 2006). Lippa's (2006) survey research, which did not collect testosterone data, did find that women, but not men, who admitted to having a high sex drive also stated they had a greater sexual attraction to both sexes. Whatever the relationship between testosterone and heightened or diminished sex drive turns out to be, it cannot account in and of itself for a woman's sexual orientation. Lisa Diamond noted that prenatal testosterone exposure did not produce a lesbian or bisexual woman. Rather, it appeared to produce a more fluid sex orientation, whereby a woman may have a periodic same-sex attraction (or be bicurious), while also preferring a heterosexual relationship (Diamond 2008). Diamond did not discuss whether a high amount of prenatal testosterone could account for a woman having a stronger sex drive. However, research on polycystic ovary syndrome, characterised by higher than normal testosterone levels in women, suggests higher reports of bisexuality and changing sexual orientation than the control group of women (Manlove et al. 2008). ${ }^{2}$

Many bisexual women acknowledged that they were sexually attracted to one sex while being emotionally drawn to forming a relationship with the other sex. Moreover, the sex they were more emotionally attracted to was the sex they wanted to form a monogamous relationship with. In contrast, the sex they were physically attracted to was the one they preferred to have 'no strings attached' sex with. Typical of these women was the following ad written by a 43-year-old bisexual who desired an emotional connection more than straightforward sexual satisfaction. She wrote that 'Men capture my attention in an instant with their muscle, strength, cologne, deep voice, a 5 o-clock shadow, the feel, smell and taste

2 Bisexual/bicurious interest may also be associated with childhood abuse. Laumann and colleagues' US sexual survey (1994) found a correlation between women who claimed to be bisexual and women who reported childhood sexual abuse. Perhaps a difficult parent-child relationship makes it more difficult to bond emotionally with one sex, contributing to a greater willingness to state a preference for both sexes. 
of them. How they are different from me'. She added, however, 'women too hold a fascination for me: softness, unexplored yet familiar territory, physical knowing, and the emotional connection. How they are similar to me'. She concluded by noting she 'longs to give the same things that I seek in another ... friendship, passion, desire, comfort, humor, tenderness, mental stimulation, soulful nourishment and perhaps even love'. For her, the stronger subjective and emotional connection was with the female or, in her words, 'her soul mate', and not the male.

Our study found that, at least for women who constructed ads on the sex website, the 'new' heterosexual female sexual persona may be essentially something of a tease to attract a potential partner's interest with little genuine interest in having a casual sexual encounter. David Buss (2008) referred to this female strategy as an example of a 'bait and switch' marketing ploy whereby a female's dress, gestures or voice are sexually suggestive, while there is no serious intention of entering into an immediate sexual tryst. The straight female profile ads suggest a sexual openness and thus availability to any and all men, while continuing to be insistent on engaging in sex only within an established relationship.

A separate, albeit related, control study featured a middle-aged male's facial photo with a profile that stated: 'have an interest in hot pleasurable sex'. Over a two-month period, the profile attracted 15 female emails. Each email was sent the same sentence: 'I think you are hot, too, let's meet.' Only two of the 15 initial females responded to the message. One female acknowledged she was a swinger and invited the man to participate in a threesome with her husband. The other reply was from a 20 -something female who sent a new set of pictures of herself wearing a bikini and asked if she 'was sexy'. A return email requesting a meeting did not receive a response. It is possible to interpret the females' correspondence with the man's profile as never being truly interested in meeting. Instead, they may have wanted to see if their overture email would invoke a reply that would mean, from their perspective, an unfamiliar man desired them. We are not alone in this interpretation: in our larger sample we would occasionally find a male ad that shouted in large bold print: 'DOES ANYONE ON THIS SITE RESPOND TO ADS AND EMAILS? COME ON LADIES!'. We did not find a single female profile wondering if anyone responds to these profiles. Nor did we find a single male profile asserting they were 'Not interested in a one-night stand' or 'No married women, please!'. More to our point, heterosexual women's (but not men's) profiles overwhelmingly and repeatedly asserted they were not interested 
in a 'ONE NIGHT STAND!'. For women who are not in a swinger relationship or identifying as bisexual, it seems that the urge to be desired is fulfilment enough.

Lisa Diamond (2008) suggested that for females there is a strong link between intimacy and sexual desirability. Women want, first and foremost, to be validated; thus, seeking casual sexual opportunities has less to do with sexual pleasure than it does with wanting to be desired. In concurrence, Marta Meana (2010) suggested that women's primary personal validation is based on a narcissistic need to be seen as sexually desirable more than it does with finding a physiological outlet for sexual fulfilment (Bergner 2009). In this way, it is significant that 20 of the 60 straight women who expressed a strong interest in 'no strings attached' sex also noted they were coming or just about to come out of 'dead marriages'. Rebound dating is often more about ego validation that one is still sexually desirable than it is about obtaining just sexual satisfaction. For example, a 24-year-old woman wrote:

I'm on the prowl for athletic guys that take very good care of their bodies and have a great style. Finally ended a bad relationship and am ready for something totally new and different. I'm fun, athletic, blond and brown with crazy night and a very active day life. If you are fat or gross don't bother, yes you know who you are. My age limit is 26, if over that don't bother.

In time, however, rebound sex dating usually leads to the establishment of another relationship. For example, a 38-year-old straight woman who was preparing to leave a sexless marriage wrote:

My situation is changing rapidly. I need something to get out of the rut. I'm not single yet, but I will be VERY soon. Looking for a guy that has his own things in life that he enjoys ... I totally believe in family, and romance for that matter, and if I was with a man that I love you would be all mine and no one else's, that's just how I feel about it.

If the bisexual, bicurious or heterosexual women coming out of a 'dead marriage' are dropped from the sample, there are only 40 women, or 7 per cent of our entire sample population, who state they are interested only in a casual sexual encounter. Of the 40 women who expressed this interest, it is difficult to know if they truly wanted a series of anonymous sexual encounters or were only using a highly suggestive ad to see who responded as a means to validate their own desirability. For women who are not in a swinger relationship or identify as bisexual, the urge to be desired may be fulfilment enough. 
At first, it may seem contradictory that females would use a sex site to find a relationship. However, as we thought more about this, it made some cultural sense. Females appear to be engaging in a form of intrasexual competition with other females. In a culture that has come to embrace sexual satisfaction as an important aspect of a satisfactory life, and where 30 per cent of the American female population reports having a low or nonexistent sex drive (Diamond 2008), it may be a good mating strategy to demonstrate the presence of a strong interest in sexual enjoyment.

\section{Conclusion}

Adult Friend Finder is the world's largest online dating site. Its home page advertises itself as being a site where men and women can find good opportunities to find like-minded people interested in casual sexual encounters. We found the site functions, however, more as a dating site in which heterosexual women, in spite of their sexually suggestive profiles, prefer to form some type of ongoing relationship. ${ }^{3}$ Straight women often

3 Not every male in our sample advertised as wanting only a casual sexual encounter. Our sample found 66 males (10 per cent) who were straightforward in acknowledging they were more interested in finding a steady girlfriend than engaging in anonymous sex. This seems to be slightly correlated with age. A majority of males ( $>50 \%$ ) from 18-39 listed casual sexual encounters as the desired motive; however, by 40 and above more men's ads stated an interest in multiple motives - that is, they continued to state a willingness for 'no strings attached' sex while also noting an openness to a longterm/romantic relationship (LTR). The correlation between men aging and desiring a LTR may not simply be an artefact of them becoming cleverer in the way they prepared their profile. For example, Mathes, King, Miller and Reed (2002) found a strong correlation between increasing age and men's desire to form stronger emotional bonds. Similarly, Del Giudice (2009) noted that, 'males throughout the world tend to shift from high mating effort in young adulthood to a phase of increased parental investment' (also see Winking et al. 2007). While our findings did see a trend for a majority of males on the website who were seeking casual sex, it is also important to note that men may not be solely seeking sex with no emotional implications. Men, too, have been noted to have romantic inclinations and fall in love just as women do. As sex and sexuality is an important facet of human evolutionary lineage, 'choosing mates carefully and establishing long-term mateship were adaptive problems faced by both sexes, not just females, throughout evolutionary history' (Salmon and Symons 2003: 68). For example, a 43-year-old wrote that his ideal person is:

someone who is not interested in one night stands or likes to sleep around ... if that's you, please pass me up ... I'm worth more than that and wish for someone who feels the same. I know that lots of women won't make it this far [reading the ad] but I trust that if you have that you will give me some feedback ... good or bad.

He added 'he would very much like to meet someone who was looking for a short term/long term lover or great friend with relationship benefits to enjoy'.

A 36-year-old man concurred and wrote, 'I am a good looking male that is currently looking for one and only one awesome lady to spend some one on one time with having fun in and out of the bed'. He added, 'There are a lot of game players out there but I am willing to wait to meet my special lady'. 
tease an interest in a 'hook up' encounter or willingness to enter into a casual sexual tryst when most have no intention of doing so. With the exception of a few heterosexual women (who were not bicurious or bisexual), our study found most heterosexual women are not interested in short-term mating for the primary purpose of seeking sexual pleasure. What American women's profiles repeatedly emphasise is the desire to form some type of ongoing relationship. This raises the never-ending question: Is the qualified caution found in women's profiles the result of lingering cultural restraint, or is it further evidence of the presence of underlying evolutionary derived sex differences? Clearly, we need renewed scholarly effort.

\section{Acknowledgements}

We would like to thank Jocie Barlett, Daniel Bergner, Dan Benyshek, Carolyn Brewer, Don Brown, David Buss, Lisa Diamond, Justin Garcia, Peter Gray, Sara Hill, Marta Meana, Tom Gregor, John Townsend, Warren Shapiro, Jen Soket and Don Symons for their suggestions, encouragement and scholarship.

\section{References}

Baumeister, Roy F. and Dianne M. Tice. 2001. The Social Dimension of Sex. Boston: Allyn and Bacon.

Baumeister, Roy F., Kathleen R. Catanese and Kathleen D. Vohs. 2001. 'Is there a gender difference in strength of sex drive? Theoretical views, conceptual distinctions, and a review of relevant evidence'. Personality and Social Psychology Review 5(3): 242-73. doi.org/10.1207/ S15327957PSPR0503_5

\footnotetext{
Men, more so than women, tended to use a broader sex strategy that suggests an openness to enter into any type of sexual encounter: 'no strings attached' sex, regular sex at a specific time or a longterm relationship. This does not mean, however, that the men did not also crave emotional intimacy. Research has documented that the desire to form a love attachment is as strong in males as it is in females (Ellison and Gray 2009; Fisher 2004; Jankowiak 1995, 2008). Other work has noted that some men try to establish an emotional relationship with prostitutes and strippers, which speaks loudly to the male need for emotional intimacy (Jankowiak and Paladino 2008). For men, the pull toward seeking sexual variety is impossible to satisfy and often undermines a man's ability to sustain his relationship based on emotional monogamy and sexual intimacy (Baumeister and Tice 2001).
} 
Bergner, Daniel. 2009. 'What do women want?' New York Times Magazine, 22 January: 1-12. Online: www.nytimes.com/2009/01/25/ magazine/25desire-t.html (accessed 1 June 2017).

Betzig, Laura. 1989. 'Causes of conjugal dissolution'. Current Anthropology 30(5): 654-76. doi.org/10.1086/203798

Bogle, Kathleen A. 2008. Hooking Up: Sex, Dating and Relationships on Campus. New York: New York University Press.

Brizendine, Louann. 2006. The Female Brain. London: Bantam Books.

Buss, David M. 2003. The Evolution of Desire: Strategies of Human Mating. New York: Basic Books.

- 2008. Evolutionary Psychology: The New Science of the Mind. $3^{\text {rd }}$ ed. Boston: Pearson.

Buss, David M. and David P. Schmitt. 1993. 'Sexual strategies theory: An evolutionary perspective on human mating'. Psychological Review 100(2): 204-32. doi.org/10.1037/0033-295X.100.2.204

Campbell, Anne. 2008. 'The morning after the night before: Affective reactions to one night stands among mated and unmated women and men'. Human Nature 19(2):157-73. doi.org/10.1007/s12110-0089036-2

Clark, Russell D. 1990. 'The impact of AIDS on gender differences in the willingness to engage in casual sex'. Journal of Applied Psychology 20(9): 771-82. doi.org/10.1111/j.1559-1816.1990.tb00437.x

Del Giudice, Marco. 2009. 'Sex, attachment and the development of reproductive strategies'. Behavorial and Brain Sciences 32(1): 1-67. doi.org/10.1017/S0140525X09000016

Diamond, Lisa M. 2008. Sexual Fluidity: Understanding Women's Love and Desire. Cambridge: Harvard University Press.

Ellison, Peter T. and Peter B. Gray (eds). 2009. Endocrinology of Social Relationships. Cambridge: Harvard University Press.

Fisher, Helen. 2004. Why We Love. New York: Henry Holt. 
Florida, Richard. 2009. Who's Your City?: How the Creative Economy is Making Where to Live the Most Important Decision of your Life. New York: Random House.

Gangestad, Stephen W. and Jeffry A. Simpson. 2000. 'The evolution of human mating: Trade-offs and strategic pluralism'. Behavioral and Brain Sciences 23(4): 573-87. doi.org/10.1017/S0140525X0000337X

Garcia, Justin R and Chris Reiber. 2008. 'Hook-up behavior: A biopsychosocial perspective'. Journal of Social, Evolutionary, and Cultural Psychology 2(4): 192-208. doi.org/10.1037/h0099345

Gray, Peter B. and Justin R. Garcia. 2013. Evolution and Human Sexual Behavior. Cambridge: Harvard University Press.

Greiling, Heidi and David M. Buss. 2000. 'Women's sexual strategies: The hidden dimension of short term extra-pair mating'. Personality and Individual Differences 28(5): 929-63. doi.org/10.1016/S01918869(99)00151-8

Grello, Catherine M., Deborah P. Welsh and Melinda S. Harper. 2006. 'No strings attached: The nature of casual sex in college students'. The Journal of Sex Research 43(4): 255-67. doi.org/10.1080/ 00224490609552324

Hatfield, Elaine, Megan Forbes and Richard L. Rapson. 2011. 'Marketing love and sex'. Society 49(6): 506-11. doi.org/10.1007/s12115-0129593-1

Hatfield, Elaine, Elisabeth S. Hutchinson, Lisamarie Bensman, Danielle M. Young and Richard L. Rapson. 2012. 'Cultural, social and gender influence on casual sex: New developments'. In Social Psychology: New Developments, edited by Jan Turn and Andrew D. Mitchell, 1-38. New York: Nova Science.

Hrdy, Sarah Blaffer. 1999. Mother Nature: A History of Mothers, Infants and Natural Selection. New York: Pantheon.

Jankowiak, William R. 1995. Romantic Passion: The Universal Experience? New York: Columbia University Press.

_- 2008. Intimacies: Sex and Love Across Cultures. New York: Columbia University Press. 
Jankowiak, William R. and Laura Mixson. 2008. "I have his heart, swinging is just sex": The ritualization of the love bond in an American spouse exchange community'. In Intimacies: Love and Sex Across Cultures, edited by Jankowiak, 245-66. New York: Columbia University Press.

Jankowiak, William R. and Thomas Paladino. 2008. 'Desiring sex, longing for love: a tripartite conundrum'. In Intimacies: Love and Sex Across Cultures, edited by Jankowiak, 1-36. New York: Columbia University Press.

Jankowiak, William, Peter Gray and Kelly Hatman. 2008. 'Globalization and perception of attractiveness'. Journal of Cross-Cultural Research 10(1-22): 248-69.

Kinsey, Alfred C., Wardell B. Pomeroy and Clyde E. Martin. 1948. Sexual Behavior in the Human Male. Bloomington: Indiana University Press.

- 1953. Sexual Behavior in the Human Female. Bloomington: Indiana University Press.

Lambert, Tracy A., Arnold S. Kahn and Kevin J. Apple. 2003. 'Pluralistic ignorance and hooking up'. The Journal of Sex Research 40(2): 129-33. doi.org/10.1080/00224490309552174

Laumann, Edward O., John Gagnon, Robert T. Michael and Stewart Michaels. 1994. The Social Organization of Sexuality: Sexual Practices in the United States. Chicago: University of Chicago Press.

Lippa, Richard A. 2006. 'Is high sex drive associated with increased sexual attraction to both sexes? It depends on whether you are male or female'. Psychological Science 17(1): 46-52. doi.org/10.1111/j.14679280.2005.01663.x

Manlove, Heidi Ann, Christelbeth Guillermo and Peter B. Gray. 2008. 'Do women with polycystic ovary syndrome (PCOS) report differences in sex-typed behavior as children and adolescents? Results of a pilot study'. Annals of Human Biology 35(6): 584-95. doi.org/ $10.1080 / 03014460802337067$

Mathes, Eugene.W., Christine A. King, Jonathan K. Miller and Ruth M. Reed. 2002. 'An evolutionary perspective on the interaction of age and sex differences in short-term sexual strategies'. Psychological Reports 90(3 pt 1): 949-56. doi.org/10.2466/pr0.2002.90.3.949 
Mealey, Linda. 2000. Sex Differences: Developmental and Evolutionary Strategies. San Diego, CA: Academic Press.

Meana, Marta. 2010. 'Elucidating women's (hetero)sexual desire: Definitional challenges and content expansion'. Journal of Sex Research 47(2): 104-22. doi.org/10.1080/00224490903402546

Meston, Cindy and David Buss. 2007. 'Why humans have sex'. Archives of Sexual Behavior 36(4): 477-507. doi.org/10.1007/s10508-007$9175-2$

Paglia, Camille. 2010. 'No sex please, we're middle class'. New York Times, 25 June, A23.

Paul, Elizabeth L. and Kristen A. Hayes. 2002. 'The casualties of 'casual' sex: A qualitative exploration of the phenomenology of college students' hookups'. Journal of Social and Personal Relationships 19(5): 639-61. doi.org/10.1177/0265407502195006

Paul, Elizabeth L., Brian McManus and Allison Hayes. 2000. “Hookups': Characteristics and correlates of college students' spontaneous and anonymous sexual experiences'. The Journal of Sexual Research 37(1): 76-88. doi.org/10.1080/00224490009552023

Pillsworth, E.G. and Martie E. Haselton. 2006. 'Women's sexual strategies: The evolution of long-term bonds and extrapair sex'. Annual Review of Sex Research 17: 59-100.

Regan, Pamela C. and Ellen Berscheid. 1999. Lust: What we Know about Human Sexual Desire. Sage Series on Close Relationships. Thousand Oaks, CA: Sage Publications.

Salmon, Catherine and Donald Symons. 2003. Warrior Lovers: Erotic Fiction, Evolution and Female Sexuality. New Haven: Yale University Press.

Schmitt, David P. 2005. 'Sociosexuality from Argentina to Zimbabwe: A 48-nation study of sex, culture, and strategies of human mating'. Behavioral and Brain Sciences 28(2): 247-75. doi.org/10.1017/ S0140525X05000051 
Schmitt, David P., Todd K. Shackelford and David M. Buss. 2001. "Are men really more "oriented" toward short term mating than women?' Psychology, Evolution and Gender 3(3): 211-39. doi.org/ $10.1080 / 14616660110119331$

Symons, Donald. 1979. The Evolution of Human Sexuality. Oxford: Oxford University Press.

Tolman, Deborah L. and Lisa M. Diamond. 2001. 'Female sexuality and sexual desire'. In Encyclopedia of Women and Gender, edited by Judith Worell. New York: Academic Press.

Toma, Catalina L., Jeffrey T. Hancock and Nicole B. Ellison. 2008. 'Separating fact from fiction: An examination of deceptive selfpresentation in online dating profiles'. Personality and Social Psychology Bulletin 34(8): 1022-36. doi.org/10.1177/0146167208318067

Townsend, John Marshall. 1998. What Women Want - What Men Want: Why the Sexes Still See Love and Commitment so Differently. Oxford: Oxford University Press.

Townsend, John Marshall and Timothy Wasserman. 1998. 'Sexual attractiveness: Sex differences in assessment and criteria'. Evolution and Human Behavior 19(3): 171-91. doi.org/10.1016/S1090-5138 (98)00008-7

van Anders, Sari M., Lisa Dawn Hamilton and Neil V. Watson. 2007. 'Multiple partners are associated with higher testosterone in North American men and women'. Hormones and Behavior 51(3): 454-59. doi.org/10.1016/j.yhbeh.2007.01.002

Winking, Jeffrey, Hillard Kaplan, Michael Gurven and Stacy Rucas. 2007. 'Why do men marry and why do they stay?' Proceedings of the Royal Society of London. B. 274(1618): 1643-49. doi.org/10.1098/ rspb.2006.0437 
This text is taken from Focality and Extension in Kinship: Essays in Memory of Harold W. Scheffler, edited by Warren Shapiro, published 2018 by ANU Press, The Australian National University, Canberra, Australia.

doi.org/10.22459/FEK.04.2018.12 